\title{
Cooperación internacional, política exterior y geopolítica de los países emergentes. El caso de México*
}

\author{
Juan Pablo PRADO LALLANDE \\ Academia de Relaciones Internacionales \\ Facultad de Derecho y Ciencias Sociales \\ Universidad Autónoma de Puebla (México) \\ Juanp.prado@correo.buap.mx \\ Rafael VELÁZQUEZ FLORES \\ Facultad de Economía y Relaciones Internacionales \\ Universidad Autónoma de Baja California (México) \\ rafael.velazquez@uabc.edu.mx
}

Recibido: 06-02-13

Aceptado: 02-11-13

\begin{abstract}
RESUMEN
México, al igual que otros países emergentes, pretende proyectar una política exterior activa en donde la cooperación internacional para el desarrollo (CID) conferida a países geoestratégicamente relevantes ha sido un propósito permanente. Más allá de ello, desde el año 2011 México vive un proceso a favor de una mayor y mejor institucionalización de los procesos inherentes a la práctica de dicha actividad, debido a que la mera concentración geoestratégica de la cooperación internacional en regiones y países resulta insuficiente, si lo que se desea es conformar una política integral de Estado a este respecto. Este artículo tiene como propósito identificar si la CID es coherente con respecto a las directrices establecidas por criterios geoestratégicos estipulados en la política exterior, revisando también el estado actual del proceso de conformación de una política pública más consolidada y eficaz en la materia. Se argumenta que si bien la CID de México, de forma congruente con las directrices de su política exterior, ha sido destinada de manera prioritaria a Centroamérica, Sudamérica y el Caribe, es imperioso que ponga en marcha de manera cabal el contenido de su reciente Ley de CID, dado que sin ello no podrá ejercer una política exterior acorde con su perfil de país emergente.
\end{abstract}

Palabras clave: México; cooperación internacional para el desarrollo; política exterior; geoestrategia; países emergentes.

\footnotetext{
* Los autores agradecen a Immanuel Brand Rivas, asistente de investigación del proyecto "La cooperación internacional y su papel como recurso político y solidario a favor de la gobernanza global y regional. Una visión desde México", actividad apoyada por la Vicerrectoría de Investigación y Estudios de Posgrado de la Universidad Autónoma de Puebla, por su dedicado apoyo en diversas tareas de investigación inherentes a este artículo. El contenido integral del mismo es responsabilidad exclusiva de los autores.
} 


\title{
International Cooperation, Foreign Policy and Emerging Countries: The Case of Mexico
}

\begin{abstract}
Mexico, like other emerging countries, aims to implement an active foreign policy where international cooperation for development (IDC) conferred to significant geostrategic countries has been a constant activity. Beyond that, since 2011 Mexico is undergoing a process in order to improve better IDC institutionalization. This is based on the fact that the mere concentration of international cooperation in geostrategic regions and countries is insufficient, if the main purpose is to create a comprehensive state policy in this regard. This paper aims to identify if the Mexican IDC is consistent with respect to the guidelines established by geostrategic criteria stipulated in its foreign policy guidelines, as well as to review the status of the current conformation process to establish a state policy in the field. It is argued that while the Mexican IDC is indeed consistent with the guidelines of its foreign policy in the sense to give priority to Central, South America and the Caribbean, it is imperative to fulfill the content of the IDC Act.
\end{abstract}

Key words: Mexico; international cooperation for development; foreign policy; geostrategic; emerging countries.

\section{Cooperação internacional, política exterior e geopolítica dos países emergentes: $O$ caso do México}

\section{RESUMO}

Assim como outros países emergentes, o México pretende projetar uma política externa ativa na qual a cooperação internacional para o desenvolvimento (CID), conferida a países de relevância geoestratégica, tem sido um propósito permanente. Além disso, a partir de 2011 o país vive um processo de maior e melhor institucionalização dos processos inerentes à prática de dita atividade, devido a que a mera concentração geoestratégica da cooperação internacional em regiões e países parece insuficiente, se o desejo é conformar uma política integral de Estado sobre o tema. Este artigo tem como objetivo identificar se a CID mexicana é coerente com as diretrizes estabelecidas por critérios geoestratégicos estipulados na política externa, revisando, outrossim, o estado atual do processo de conformação de uma política pública mais consolidada e eficaz na matéria. Argumenta-se que embora a CID do México, de forma congruente com as diretrizes de sua política externa, tenha sido destinada de maneira prioritária à América Central, América do Sul e o Caribe, é fundamental que se ative de maneira integral o conteúdo da recente Lei de CID, já que sem isso não poderá exercer uma política externa sintonizada com seu perfil de país emergente.

Palavras chave: México; cooperação internacional para o desenvolvimento; política externa; geoestratégia; países emergentes.

\section{REFERENCIA NORMALIZADA}

Prado Lallande, Juan Pablo, y Velázquez Flores, Rafael (2013) “Cooperación internacional, política exterior y geopolítica de los países emergentes. El caso de México". Geopolítica(s). Revista de estudios sobre espacio y poder, vol. 4, núm. 1, 107-135.

SUMARIO: Introducción. 1. Política exterior, geoestrategia y cooperación internacional de los países emergentes. 2. La cooperación internacional mexicana. Aspectos generales desde el plano histórico, geoestratégico e institucional. 3. La cooperación internacional para el desarrollo de México en su dimensión de 
instrumento geoestratégico de política exterior en el año 2012. 4. Actuales transformaciones institucionales de la cooperación internacional para el desarrollo de México. 5. Del riesgo a la incertidumbre. Consideraciones finales. Bibliografía.

La mayoría de los países emergentes se encuentran en un proceso de transformación institucional, con miras a instrumentar, reforzar o reformar sus respectivos sistemas y estructuras de cooperación internacional para el desarrollo.

Penny Davies

\section{Introducción}

China, Brasil, India, Turquía, Arabia Saudita, Tailandia, Sudáfrica, México y muchos otros países emergentes coinciden en diversos ámbitos. Normalmente, todos ellos buscan proyectar una política exterior activa como uno de sus rasgos más distintivos. Su objetivo es reflejar una mayor presencia en el sistema internacional y ser actores relevantes en el mismo. En ese marco, tales países han puesto en marcha ambiciosas políticas de Cooperación Internacional para el Desarrollo (CID) de forma coincidente con sus intereses más apremiantes desde la perspectiva geoestratégica. En este sentido, por un lado, la constante es que en la actualidad dichos Estados realizan una amplia gama de actividades de CID, mediante la instrumentación de múltiples proyectos, programas y asociaciones de colaboración con países prioritarios. Por el otro lado, dichas acciones son instrumentadas mediante renovados mecanismos jurídicos e institucionales dedicados a gestionar y conducir tales tareas, con criterios y procedimientos afines a los propósitos de política exterior de sus practicantes.

Esto es relevante dado que en años recientes esta gama de países, al carecer de suficientes recursos de poder "duro", y como una suerte de ejercicios de poder "blando", recurren de forma cada vez más frecuente al ejercicio de la CID mediante la modalidad Sur-Sur. Lo anterior, más allá de acciones solidarias a favor de terceros, es también realizado con el fin de ejercer mayor presencia e influencia en el entorno geográfico de su predilección. Su propósito es satisfacer mediante este instrumento de política exterior intereses nacionales previamente definidos, $\mathrm{y}$, de paso, posicionarse frente a la tradicional colaboración ofrecida por los países desarrollados, así como de otros oferentes del Sur, lo cual ha impreso un renovado dinamismo a las relaciones internacionales de nuestros días.

Dicho de otro modo, "La CID si bien constituye un modesto elemento de las múltiples manifestaciones de la agenda política y económica exterior de los países emergentes, hoy en día esta actividad comprende un rol tal que está consiguiendo transformar la geografía del poder mundial" (Mawdsley, 2012: 12) En este contexto, 
México, un país emergente cuya adscripción geográfica se debate entre Norteamérica y Latinoamérica, coincide con los fenómenos previamente señalados. Lo hace en términos de instrumentar una vasta cuantía de ejercicios de CID al Sur de su frontera mediante la recién creada (septiembre de 2011) Agencia Mexicana de Cooperación Internacional para el Desarrollo (AMEXCID). Esta novedosa instancia es fruto de una innovación jurídica que pretende reposicionar a este país en el creciente empeño de los actores emergentes más importantes, en términos de conformar una política pública consolidada en la materia, alineada a las disposiciones de política exterior.

Con base en estas apreciaciones, este artículo tiene como propósito esencial identificar si la CID mexicana, en términos de sus acciones dirigidas a terceros países, es coherente con respecto a las directrices establecidas por criterios geoestratégicos estipulados en la política exterior y otros mecanismos legales y programáticos. Es decir, este trabajo busca confirmar si en efecto México le confiere prioridad a Centroamérica, Sudamérica y el Caribe mediante su oferta de colaboración externa. De forma adicional y complementaria a lo anterior, el texto revisa también el estado actual del proceso de conformación de una política pública más eficaz en la materia, tomando como referente el contenido de la Ley mexicana de CID, en vigor a partir de abril de 2011.

El argumento central de esta investigación plantea que la orientación geoestratégica de la CID mexicana dirigida a países prioritarios es una estrategia necesaria mas no suficiente del proceso de conformación de una política pública en este segmento de su política exterior. Por lo tanto, es necesaria la instrumentación integral del actual andamiaje jurídico institucional que la Ley de CID de México estipula, misma que al momento presente (diciembre de 2013) continúa en proceso de cabal aplicación.

Para alcanzar el propósito y demostrar el argumento, el ensayo se divide en seis secciones. Luego de esta introducción, el primer apartado aborda la relación entre política exterior, geoestrategia y cooperación internacional desde la perspectiva de los países emergentes. En ese apartado se señala que la identificación geoestratégica de los países destino para atender propósitos esencialmente políticos y económicos si bien es un requerimiento necesario y convencionalmente practicado, no es condición suficiente en el proceso para formular políticas de Estado en dicho tema. Ello debido a que el reforzamiento institucional de la CID en su conjunto es pieza clave para ello. Con base en ello, la segunda sección describe la simbiosis entre política exterior mexicana y su inherente CID desde la perspectiva histórica, jurídica e institucional; esto último hasta abril de 2011, cuando entró en vigor la Ley referida. Tras ello, el estudio se dedica a mostrar la manera en que México realiza ejercicios de oferta de CID a aquellas regiones y países geoestratégicamente prioritarios, tomando como referente el año 2012, es decir los datos oficiales más actualizados a este respecto. Tras ello el texto aborda tanto las innovaciones institucionales emanadas con la puesta en marca de la Ley de CID el 16 de abril de 2011, como los 
retos latentes a este respecto, los cuales se sintetizan en avances en aspectos clave, aunque también de incompleta instrumentación de sus preceptos, a más de dos años de su vigencia formal. Las consideraciones finales argumentan que, dados los datos aquí presentados, es evidente que la instrumentación de la CID de México es coherente con respecto a las directrices establecidas por criterios geoestratégicos esgrimidos por la política exterior, así como por las disposiciones que al respecto han sido establecidas por la Ley mexicana de CID. Sin embargo, si bien la cooperación mexicana cumple con esta premisa elemental, el hecho de que el andamiaje jurídico institucional que se desprende de la referida Ley, a pesar de registrar avances continúa en proceso de cabal aplicación, condiciona el camino a favor del establecimiento de una política pública en este segmento de la política exterior del país referente, situación que se asemeja a lo que ocurre en otros países emergentes.

\section{Política exterior, geoestrategia y cooperación internacional de los países emergentes}

Desde hace unas tres décadas los países emergentes se han caracterizado por reforzar sus respectivas políticas de cooperación internacional mediante la modalidad Sur-Sur (CSS). Es decir, ofrecen con cada vez mayor dinamismo colaboración a países homólogos. Lo anterior conduce a que en varios casos estos países replican el esquema clásico Norte-Sur, en el sentido de ofrecer apoyos a países de menor nivel de desarrollo relativo respecto al oferente, aunque en diversos casos también lo hacen mediante esquemas más horizontales, lo cual varía dependiendo del perfil y capacidades de los países involucrados. Ahora bien, más allá o además del criterio solidario como fundamento para otorgar colaboración técnica, científica, educativa cultural, etc., a terceros, los oferentes de CSS en lo general y los países emergentes en lo particular suelen sustentar el despliegue de dichas acciones con base en preceptos de política exterior. En este sentido, y como es sabido, en el marco de la instrumentación de esta actividad el interés nacional es promovido mediante acciones con incidencia en espacios extraterritoriales.

De ahí que los programas de CSS de los países emergentes son recurrentemente sustentados en intereses nacionales de perfil económico y político (Quadir, 2013: 328). Las referidas actividades son proyectadas de forma escalonada conforme a la prioridad geoestratégica de determinadas regiones y países respecto a los propósitos del proveedor en cuestión. Lo anterior revela que, al menos desde esta perspectiva, la CSS no se diferencia del todo respecto a la colaboración Norte-Sur, en el sentido de que ambas, si bien son formuladas como efecto de múltiples motivaciones, en el fondo responden a propósitos internos supeditados a las preferencias espaciales condicionadas por una especie de mélange de proximidad geográfica, nexos históricos, políticos, económicos, culturales y solidarios. 
Desde esta visión, "la relación simbiótica y directa entre ayuda, política exterior y de seguridad, intereses económico-comerciales y proyección de poder inherente a la cooperación Norte-Sur se aplica integralmente al caso de la cooperación Sur-Sur" (Benzi y Zapata, 2013: 68). Si bien es cierto que la CSS no es en exclusiva una acción concertada que responde a propósitos premeditados en la esfera de la política exterior de los Estados ${ }^{1}$, posturas más agudas en este sentido señalan que "son los intereses de los proveedores de CSS, que están motivados políticamente, los que explican la orientación geográfica y sectorial de su cooperación técnica y financiera, en mayor medida que las necesidades de los receptores" (Domínguez, 2013: 12).

En síntesis, la CSS conferida por los países emergentes está provista de múltiples propósitos que en su dimensión de instrumento de política exterior tienen como fin prioritario - mas no exclusivo- atender prioridades nacionales, en donde la constante es su ubicación espacial priorizada por criterios geoestratégicos. En otras palabras, una especie de determinismo geográfico define la orientación de las actividades a ser implementadas por los oferentes de la CSS, tal y como frecuentemente ocurre en el esquema Norte Sur. En suma, el tener claro las regiones y países en donde será dispuesto el ofrecimiento de cooperación internacional, con miras a atender determinados propósitos direccionados por la política exterior del oferente, es la constante en el ámbito de la CID en lo general y en la CSS en lo particular. Ahora bien, más allá del criterio geoestratégico (una práctica común en diversos países) el diseñar las estrategias adecuadas para reforzar y conducir a la CID no es, en ningún sentido, una tarea sencilla de conseguir dada la complejidad programática e institucional que conlleva poner en marcha regulaciones a este tipo de actividades gubernamentales de proyección exterior.

En el caso que nos ocupa "prácticamente todos los países del Sur carecen de una estructura organizacional necesaria para revisar sus políticas de cooperación externa, responder a los nuevos retos de desarrollo, o reorganizar sus prioridades nacionales a ese respecto mediante procesos adecuados [...] en donde la ausencia de cánones de coordinación a nivel nacional también complica su otorgamiento" (Quadir, 2013: 328). Para revertir tal situación, la cooperación internacional practicada por este segmento de países y en especial en Latinoamérica se caracteriza por cambiantes configuraciones institucionales practicadas en años recientes (Erthal y Marcondes, 2013: 47). El objetivo es ir más allá de la mera identificación geopolítica y funda-

\footnotetext{
${ }^{1}$ Por señalar otras perspectivas, en este caso de corte económico, Joaquín Tres, funcionario del Banco Interamericano de Desarrollo, menciona que "[1] CSS ha surgido gracias al crecimiento sostenido y a la reducción de la pobreza en las economías emergentes y PRM, al aumento del comercio, IED y flujos de financiamiento Sur-Sur ya la necesidad de intercambiar conocimiento y experiencias de desarrollo, que han resultado en un mundo multipolar consolidado después de la crisis del 2008" (Tres, 2013: 18). Otro fundamento hasta donde se sabe insuficientemente explorado son las migraciones como factor de cohesión supra e internacional, la disminución de la colaboración Norte Sur hacia Latinoamérica, entre muchos otros factores.
} 
mentación de su proactividad a este respecto, a través del establecimiento de novedosos mecanismos que contribuyan a "gobernar" este tipo de procesos. Ello en el sentido de conseguir resultados de manera más predictible, en línea con el interés nacional, la política exterior de los actores inmersos en su praxis, así como de manera coincidente con los propósitos generales de la agenda global del desarrollo (Prado, 2011).

En aras de conseguir tal aspiración, si bien no existen procedimientos definidos, se han identificado algunos elementos a favor de una mejor institucionalización de la CID que cada país de forma soberana - $\mathrm{o}$ de forma discrecional, en lenguaje no diplomático- decide practicar. Los elementos más sobresalientes a este respecto son: contar con personal capacitado, lineamientos jurídicos, presupuesto, directrices de gestión claras, sistemas de monitoreo y evaluación, así como una institución coordinadora (Mawdsley, 2012: 93). A este respecto, precisamente este asunto -el déficit de institucionalidad de la CID, así como renovados esfuerzos para encarar y superar gradualmente tal condición- es el común denominador de los países emergentes, en donde como se verá enseguida México no es una excepción.

\section{La cooperación internacional mexicana. Aspectos generales desde el plano histórico, geoestratégico e institucional}

En su dimensión de instrumento de política exterior, la CID de México ha sido históricamente una actividad que ha pretendido en su acepción receptora complementar capacidades nacionales en términos de desarrollo interno. Desde la perspectiva oferente, México ha procurado contribuir a la atención de propósitos internos del orden político, económico e inclusive en términos de seguridad mediante acciones solidarias, dirigidas de manera preferencial hacia países geoestratégicamente relevantes. Así, la oferta de cooperación mexicana, al igual que sucede en otros países, constituye una actividad soberana de política exterior con miras a atender de forma preferencial las aspiraciones nacionales y tras ello apoyar a países afines. Dicho de otro modo, junto a la satisfacción de su interés nacional, las acciones de cooperación mexicanas en su dimensión de política exterior pretenden reforzar sectores clave del desarrollo de sus receptores, especialmente en aquellos países de su entorno geográfico más próximo, en donde existen lazos históricos, políticos, económicos y culturales que propician este tipo de interacciones. Ello devela que en el marco del ejercicio de la CID y naturalmente la CSS el impulso al interés nacional, la instrumentación de política exterior y la práctica de cooperación internacional con propósitos desarrollistas y solidarios, pueden ser criterios y acciones com- 
patibles entre sí, aunque instrumentar una plena política coherente de desarrollo resulte una tarea compleja de conseguir ${ }^{2}$.

En el caso mexicano, dado su relativo nivel de desarrollo, que le ha permitido compartir conocimientos de vanguardia y experiencias exitosas en diversos sectores, así como en razón a la voluntad política para instrumentar este tipo de acciones, la cooperación internacional en su faceta oferente ha sido practicada de forma persistente durante cuatro décadas, teniendo como principales referentes Centroamérica, el Caribe y Sudamérica. A partir de 1970, luego de practicar una política exterior pasiva, defensiva y juridicista - lo cual ameritaba que en el ámbito de la CID México se limitara a actuar como un cauto receptor de asistencia técnica一, el gobierno del presidente Luis Echeverría (1970-1976) daría un giro a este respecto a fin de instrumentar una política exterior de perfil activo. Las causas que llevaron a este cambio de estrategia se enmarcan en los cambios en el orden internacional de principios de los 1970, la crisis económica interna, así como a los recientes movimientos de izquierda en oposición al gobierno federal. Por estos factores internos y externos, Echeverría tuvo que proyectar una presencia importante del país en el ámbito internacional.

En este contexto, la incipiente cooperación internacional practicada a partir de este momento, en línea con las nuevas directrices de una activa política exterior, pretendería servir de forma pragmática como un instrumento político a favor de los intereses del gobierno en turno, así como del reposicionamiento nacional en el entorno hemisférico. Un claro ejemplo en ese sentido fue la ayuda otorgada por el presidente Echeverría —artífice de la matanza de estudiantes que en 1968 se manifestaban solicitando mayores espacios de democracia- al gobierno de Salvador Allende en Chile en 1972, país sudamericano que sufría de un bloqueo financiero internacional como represalia a su política de expropiación. Con la línea crediticia mexicana a favor de dicho país austral, Echeverría pretendía legitimar internamente su gobierno frente a los movimientos de izquierda nacionales, mediante el mensaje de que mientras al interior del país esta tendencia política-ideológica le criticaba, en el exterior se le reconocía (Ojeda, 1986: 66-70).

A manera anecdótica, pero representativa del fenómeno en cuestión, el uso político de la cooperación mexicana fue más que evidente cuando en 1972, tras recibir los mencionados apoyos financieros, Salvador Allende señaló que "la revolución no pasa por la Universidad [...] la revolución pasa por las grandes masas, la revolución

\footnotetext{
${ }^{2}$ Dicha postura podría ser interpretada como una suerte de mezcla de los dos primeros modelos de relación entre política exterior y política de CID que Manuel de la Iglesia Caruncho propone. En el primero de ellos, la CID es un instrumento de política exterior. En el segundo modelo, la CID es un elemento, entre otros, definitorio de la política exterior. La tercera posibilidad, según dicho autor, la política de cooperación influye en otras políticas de impacto en los beneficiarios, erigiéndose como una política de desarrollo (Iglesia, 2011: 1).
} 
la hacen los pueblos, esencialmente los trabajadores" (ibídem.). El mensaje de Allende fue dirigido a los estudiantes durante una visita a la Universidad de Guadalajara en México - en donde la agitación política de izquierda en contra el gobierno se acrecentaba- A todas luces, ese señalamiento era un claro respaldo a su colega, financiador y cooperante, el presidente mexicano Echeverría.

Ya entrada la década de los 1980 la cooperación de México se desplazaría hacia Centroamérica, la cual pasaba por un contexto de guerras internas e inestabilidad política, social y crisis económica que se harían cada vez más evidentes. De la ayuda militar (no oficial) a los sandinistas, al Grupo Contadora (1983), el Pacto de San José (1980), la Cumbre de Esquipulas II (1987), pasando por múltiples apoyos financieros y técnicos bilaterales, el gobierno mexicano desplegó una amplia gama de instrumentos y modalidades de colaboración hacia esta atribulada región, de la cual dependía en buena medida la estabilidad y seguridad mexicana. En todos los casos, México ofrecía estos apoyos bajo la lógica de otorgarse a sus respectivos beneficiarios, siempre y cuando tales acciones atendiesen de forma coincidente con aspiraciones solidarias a los intereses mexicanos en la región. ¿Cuáles eran esos intereses? En esencia, eran promover la estabilidad política frente a sublevaciones armadas, moderar a los sectores revolucionarios y evitar la intervención militar estadounidense en la zona y neutralizar tales conflictos con respecto a la confrontación este-oeste (Ojeda, 1986). Todo ello bajo la óptica de que tales disturbios eran generados por históricas injusticias sociales, las mismas que, de no contenerse mediante acciones diplomáticas y cooperativas a favor del desarrollo, afectarían sensiblemente a la seguridad y soberanía de México. De ahí que en este contexto, la CID mexicana conferida durante la década de los 1980 y 1990 mediante diversos canales de forma preferencial a Nicaragua, Guatemala, El Salvador, Honduras y los demás países centroamericanos conformaría un elemento esencial de su política exterior en esta región prioritaria del país.

Si bien a partir de entonces México configuró la CID para atender propósitos nacionales condicionados por la coyuntura histórica en cuestión, este instrumento colaborativo respondería desde entonces hasta hoy en día al objetivo geoestratégico de procurar mantener o afianzar su presencia política y económica de forma prioritaria en Centroamérica, pasando por Sudamérica y el Caribe (en ese orden). En este sentido, la CID serviría como un elemento complementario y legitimador de los procesos políticos y económicos referidos, aunque también como un ejercicio que responde de forma legítima a la anuencia por parte de los mexicanos para que se eroguen recursos para financiar este tipo de actividades a favor de los pueblos centroamericanos ${ }^{3}$.

\footnotetext{
${ }^{3}$ Así lo indica los resultados de la encuesta "México, las Américas y el Mundo 2012", en donde se señala que en México el $49 \%$ de las personas encuestadas aprueban que su gobierno destine recursos para el
} 
De manera afín a tal aseveración, Rocha señala que México, al pretender construir una suerte de hegemonía regional en Centroamérica, recurre al establecimiento de relaciones sustentadas en preceptos geopolíticos y geoeconómicos mediante el ejercicio de la cooperación al desarrollo (Rocha, 2006: 56). Lo anterior evidencia que en realidad la CID conforma un medio y no un fin mismo puesto que el propósito esencial era contribuir, en su perfil de instrumento de política exterior, a alcanzar otros objetivos más relevantes (geopolíticos y geoeconómicos). En menos palabras, la idea era afianzar la relación política y económica de México en Centroamérica, Sudamérica y el Caribe y fomentar el desarrollo mediante la cooperación internacional. Si bien es una tarea relevante en sí misma, en realidad México se convierte en un facilitador para conseguir los citados propósitos de más onda envergadura (ibídem). Ante estas actividades, la CID de México ganó reconocimiento y estatus nacional e internacional. Ello se vio reflejado en 1988 cuando el Congreso mexicano incluyó en la Constitución a la CID como un principio rector de la política exterior.

En el plano institucional, en 1951, la Secretaria (Ministerio) de Relaciones Exteriores (SRE) creó la Dirección General de Organismos Internacionales. Mediante esta oficina el país gestionaba la recepción de asistencia técnica proveniente de instancias multilaterales, mientras que la entonces Dirección General de Asuntos Bilaterales hacía lo propio con el ofrecimiento de colaboración ofrecida por países donantes. En el marco de la referida política exterior activa, en 1971 el gobierno mexicano creó la Dirección General de Cooperación Técnica y Científica Internacional (DGCTC), cuya labor sería promover la colaboración mexicana en la dimensión receptora y oferente. Ésta contribución, como se ha visto, se orientó principalmente hacia Centroamérica, el Caribe y Sudamérica, en respuesta a los lineamientos trazados por la política exterior del momento.

Con la CID elevada a rango constitucional, la cooperación de México se reformula y refuerza su proceso de institucionalización. En 1990, el gobierno creó la Comisión Mexicana de Cooperación con Centroamérica. Un año después se celebró la primera Cumbre del Mecanismo de Diálogo y Concertación de Tuxtla, mientras que para 1994 la citada Comisión amplía su margen de acción a El Caribe, año en que se conforma la Subsecretaría de Cooperación Internacional. Por su parte, en el año 2000, la canciller Rosario Green establecería el Instituto Mexicano de Cooperación Internacional para el Desarrollo (IMEXCI), con miras a que tras un proceso de maduración sentara las bases de una agencia de esta naturaleza.

desarrollo de Centroamérica, mientras que el 71\% de los líderes encuestados avala tales acciones (Comunicado de Prensa de AMEXCID: "La cooperación internacional para el desarrollo en la encuesta 'México, las Américas y el Mundo",, 24 de junio de 2013). 
Este continuum de ascenso institucional de la CID mexicana se desaceleraría y de hecho retrocedería cuando llega al poder el presidente Vicente Fox (2000-2006), quien provenía del derechista Partido Acción Nacional. Al amparo de este gobierno de perfil conservador, en donde las relaciones económicas-comerciales son prioritarias respecto a las relaciones político-diplomáticas, la nueva estructura de la SRE fue diseñada de modo tal que atendiese a dicha orientación. Fue así como una de las primeras acciones de este gobierno en el año 2000 fue desmembrar al IMEXCI, bajo el argumento del entonces canciller Jorge G. Castañeda de que la CID no era prioritaria, dado que "una oficina de cooperación internacional sin suficientes recursos no puede operar" ${ }^{4}$, dejando en un segundo plano el referido principio constitucional a favor de la CID, así como el acervo generado a éste respecto años atrás. Así, en lugar del IMEXCI, Castañeda creó la Subsecretaría de Relaciones Internacionales y Cooperación Internacional, en donde la CID fue en buena medida relegada por otras Direcciones Generales dedicadas a promover de manera preferencial las relaciones económicas internacionales, aunque la DGCTC continuó haciendo su labor gestionando una cartera de unos 450 proyectos anuales, promedio.

En 2004 tal Subsecretaría cambió su nombre por el de "Unidad" (URECI), cuya conformación se mantuvo durante el gobierno de Felipe Calderón, del mismo partido que Fox. No sobra decir que en particular en la era Fox la CID como instrumento proactivo de política exterior si bien continuó ofreciendo colaboración a Centroamérica, el Caribe y Sudamérica, fue relegada en un segundo plano, siendo utilizada de forma aislada y reactiva para procurar conseguir algunos propósitos del orden político o económico, según cada caso. Una experiencia a este respecto de uso de la CID con fines políticos fue la interrupción por varios meses de 2000 de la CID mexicana hacia la República Dominicana. Ello fue debido a que en 1999 Santo Domingo se había postulado como candidato a miembro no permanente en el Consejo de Seguridad de Naciones Unidas representando a Latinoamérica, y, al no sumarse a la improvisada candidatura mexicana para el mismo cargo promovida por el presidente Vicente Fox, el país caribeño fue sancionado por la Cancillería de Tlatelolco, viendo congelado su programa de colaboración bilateral con México. Por otro lado, posiblemente el ejemplo más evidente del uso político de la cooperación mexicana en años recientes fue la oferta de becas y materiales de construcción a los países caribeños, a cambio de votos en el proceso para elegir al nuevo Secretario General de la OEA en el año 2005. En esa ocasión, el candidato mexicano, el entonces canciller Luis Ernesto Derbez, perdió ante José Miguel Insulza 5 .

\footnotetext{
${ }^{4}$ Entrevista concedida a Juan Pablo Prado Lallande, marzo de 2005.

${ }^{5}$ Por cierto, como una medida reactiva ante este fracaso, el gobierno mexicano retiró de la cuenta número 33 en ese organismo más de seis millones de dólares, a efecto de depositarlos en la Secretaría General Iberoamericana, en franco desaire a la referida instancia hemisférica.
} 
Una última experiencia a este respecto es el Plan-Puebla-Panamá (PPP). Este mecanismo era una estrategia de integración económica mexicana propuesta por el presidente Fox y secundada por Felipe Calderón (bajo el denominativo "Proyecto Mesoamericano) hacia Centroamérica y Colombia. El PPP, al tener "una proyección geoestratégica hacia esta región, área privilegiada por México en sus aspiraciones geopolíticas" (Florido y Villaruel, 2007: 72), ha recurrido a determinados ofrecimientos de CID a favor de los países participantes como una medida de legitimación de la penetración mexicana en los mercados e inversiones en Centroamérica.

Más allá de lo referido, debido a su debilidad institucional, la CID en ambos sexenios fue relegada a segundo plano por consideraciones de orden económico. A lo anterior habrá que recordar que durante el gobierno del presidente Calderón, la cooperación internacional en seguridad recibida por Estados Unidos ocupó el espacio preferencial de la política exterior en este sexenio (cfr. Covarrubias, 2013: 462).

Por otro lado, en la administración calderonista, la política exterior no fue una actividad relevante para el presidente en turno y, por ende, fue de "bajo perfil" (Chabat, 2013: 733). Todo indica que la CID no fue utilizada — ni siquiera de manera reactiva o coyunturalmente como lo hizo su antecesor- para contribuir a la obtención de réditos políticos en el plano internacional. En cambio, tal mecanismo fue usado para respaldar o acompañar las relaciones con países aliados, en especial con Centroamérica, Sudamérica y el Caribe, gracias a la inercia programática, operativa e institucional en este rubro de la interacción exterior del país referente.

Retomando el plano institucional, es importante señalar que la URECI existió hasta septiembre de 2011. La Unidad se convirtió en la Agencia Mexicana de Cooperación Internacional para el Desarrollo (AMEXCID) gracias a una iniciativa de Ley propuesta por Rosario Green, en su papel de senadora por parte del Partido Revolucionario Institucional (opositor al PAN). El propósito de este marco legal fue poner orden y reforzar desde las perspectivas política, institucional y operativa a la CID mexicana. Independientemente de lo anterior, por el número de ejercicios realizados año tras año, y como un efecto inercial respecto al activismo mexicano en las dos décadas anteriores, la CID mexicana ha contado con un significativo conglomerado de actividades, cuyos principales rasgos, ejes temáticos y orientaciones geoestratégicas son mostrados en el siguiente apartado.

\section{La cooperación internacional para el desarrollo de México en su dimensión de instrumento geoestratégico de política exterior}

El objetivo de este apartado es mostrar que, como lo hacen otros países emergentes, México realizó ejercicios de ofrecimiento de CID a aquellas regiones y países geoestratégicamente prioritarios, en este caso a la luz de las directrices de política exterior del presidente Felipe Calderón, tomando como referente el año 2012, es 
decir los datos oficiales más recientes a este respecto ${ }^{6}$. En primer lugar, para hacer una evaluación en cuanto a la correspondencia del despliegue de la CID para atender propósitos y destinos prioritarios, debe tenerse claro cuáles fueron las principales directrices en materia de política exterior por parte de la presidencia de Felipe Calderón (2006-2012). En ese sentido, el Plan Nacional de Desarrollo 2007-2012 (PND) expresa que "la política exterior de nuestro país debe ser responsable, clara y activa, mediante la cual México sea un auténtico promotor del desarrollo humano de los pueblos" (Presidencia de la República, 2006: 118). Bajo el entendido de que la política exterior de México se fundamenta en la defensa y promoción activa del interés nacional "en virtud de la herencia histórica e identidad cultural mexicanas, y porque el país comparte retos y aspiraciones con América Latina y el Caribe, la región será siempre prioritaria para México, que buscará ser siempre un actor central en la región" (ibíd.: 119). En ese tenor, el PND indica que "México reconoce su responsabilidad con sus vecinos del Sur, y en particular con Centroamérica, para promover el bienestar social y el desarrollo económico de la región como las fuentes principales de solución a problemas comunes como la pobreza, la marginación, la desigualdad y la pérdida de capital humano por la migración" (ibídem).

Frente a ello, la estrategia 8.1 de dicho documento alude a la obligación por parte del gobierno nacional de "[r]eforzar y extender los lazos políticos, económicos y culturales con América Latina y el Caribe a efecto de tener una proyección política y una presencia económica que asegure espacios de interlocución y concertación acordes con la estatura internacional del país" (ibíd.: 123) Por su parte, el referido Plan señala que "la responsabilidad del país con Centroamérica se enfocará en elevar el bienestar social y el desarrollo económico de la región". Respecto a el Caribe, el documento identifica la zona como "la tercera frontera" mexicana, señalando que "debe verse como una zona de encuentro para fortalecer relaciones políticas, comerciales, turísticas y culturales" (ibídem).

En cuanto a la CID, el PND no le confiere de manera explícita un papel relevante. Sin embargo, el documento señala que "para hacer frente a la multiplicidad de temas en el ámbito internacional, la política exterior de nuestro país atenderá en todo momento la prioridad de la cooperación internacional y estará regida por el principio de la promoción de la paz entre las naciones" (ibíd.: 11). Salta a la vista que el único subapartado del PND que hace referencia formal a la cooperación internacional es el rubro de la seguridad (y no el del desarrollo), estableciéndose como objetivo prioritario: "Fortalecer la cooperación internacional para contribuir a los esfuerzos nacionales en materia de seguridad y defensa de la soberanía" (ibíd.: 123). Ello corrobora la propensión de dicha administración a establecer, por encima

\footnotetext{
${ }^{6}$ Para ello, entre otros documentos, se ha utilizado el estudio "Informe Anual de Cooperación Técnica y Científica 2012", editado por la AMEXCID.
} 
de otros aspectos, a la seguridad como la principal política pública nacional en este periodo.

Más allá de este tipo de preceptos programáticos, la realidad fue que, como se ha señalado para Calderón, la política exterior no resultó prioritaria debido a que la creciente inseguridad requería de una mayor parte de los esfuerzos nacionales, institucionales y hasta personales para enfrentarla. A su vez, la muy reducida legitimidad de la figura presidencial en este sexenio - Calderón triunfó con apenas el $0,5 \%$ de votos respeto a su más cercano contrincante- le obligaba a concentrarse en aspectos nacionales, evitando así que la política exterior fuese un nicho de oportunidad para eventuales críticas o fricciones con los partidos opositores y población en general. Como un efecto directo de tal situación, la CID no sería ni por mucho un instrumento proactivo de la por sí relajada política exterior.

Cuadro 1. Datos generales cooperación internacional para el desarrollo de México 2012

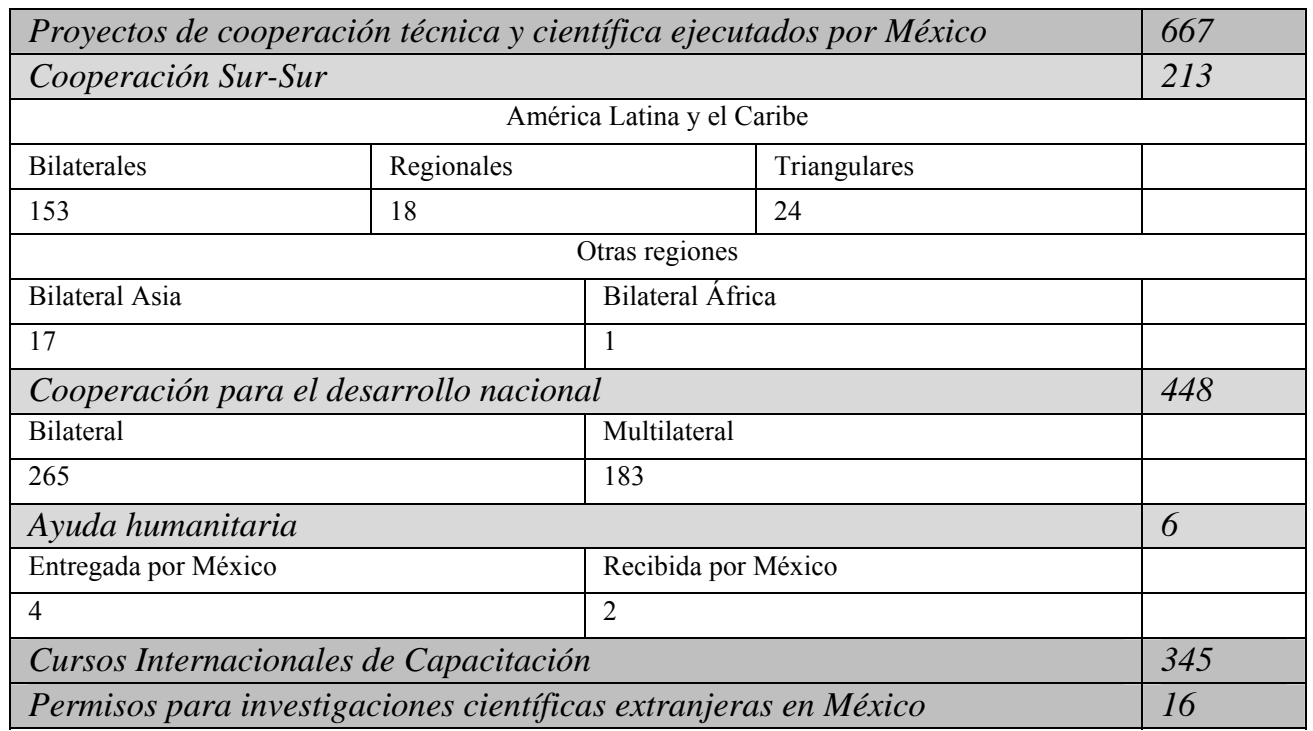

FUENTE: AMEXCID (2013a: 2).

Ya en el terreno práctico de la CID - a pesar de los vaivenes en torno al respaldo político conferido a la CID-, México ha conseguido generar una inercia programática tal que le ha permitido instrumentar en años recientes una cuantía del orden de los 550 proyectos anuales, promedio. En ese sentido, la AMEXCID reporta que en el año 2012 México instrumentó 667 proyectos - 20\% más que en 2011- (Cuadro 1), en donde la gran mayoría, 414 - es decir, el 62,5\% -, responden a la demanda de este tipo de acciones en territorio nacional, mediante apoyos 
provenientes de terceros donantes. 213 proyectos $(37,5 \%)$ correspondieron a la oferta mexicana mediante Cooperación Sur-Sur (AMEXCID, 2012). Estos datos, que coinciden con años anteriores ${ }^{7}$, son relevantes dado que evidencian que -ya sea de manera programada o como un efecto inercial- la AMEXCID es en realidad una instancia dedicada en buena medida a gestionar proyectos de instrumentación nacional. Por lo tanto, el diseño y el seguimiento de proyectos mexicanos en terceros países pasan a un segundo plano. En cuanto a la CSS mexicana es claro que, de forma coherente con respecto a los propósitos de política exterior, esta actividad estuvo orientada a reforzar su interacción con Latinoamérica y el Caribe. En este sentido, la CID mexicana fue dirigida de manera preferencial hacia dichas regiones en un $91 \%$. De este porcentaje, Centroamérica en particular acaparó el 38\% de los mismos (AMEXCID, 2012: 2). Con esta política de cooperación, Felipe Calderón buscaba recomponer las relaciones con América Latina que fueron dañadas durante el sexenio de Fox cuando su administración tuvo conflictos con Cuba, Venezuela, Argentina, Bolivia, entre otros.

En este contexto, la AMEXCID realizó un total de 212 proyectos de CSS en el ámbito técnico-científico. De ellos, 195 fueron instrumentados en América Latina y el Caribe, mientras que 17 lo hicieron en Asia-Pacífico y 1 en África (AMEXCID, 2013a: 6). A este respecto, 153 de estos proyectos fueron desplegados mediante el esquema bilateral, 18 a través de programas regionales, mientras que 24 lo hicieron por conducto de la colaboración triangular (Gráfico 1).

\section{Gráfico 1. Oferta mexicana de Cooperación Sur-Sur hacia América Latina y el} Caribe por modalidad de colaboración, 2012

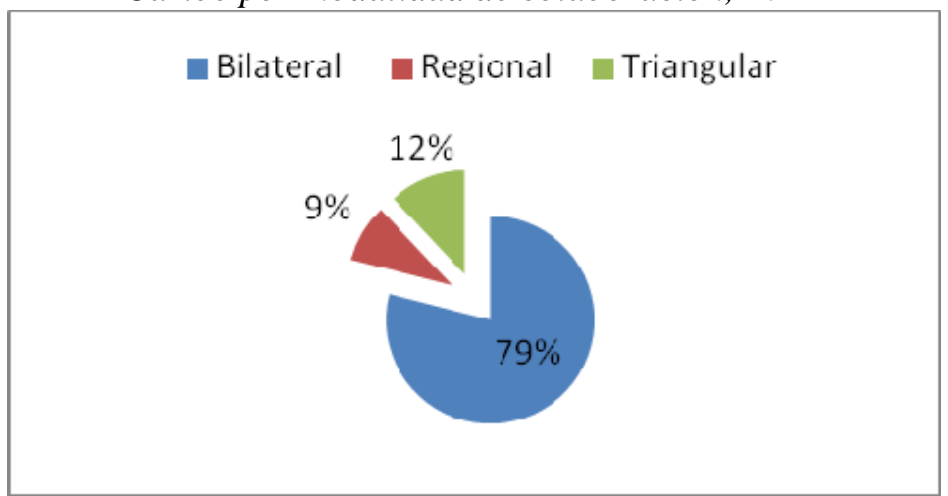

FUENTE: AMEXCID (2013a: 6).

\footnotetext{
${ }^{7}$ Por ejemplo, en 2011, de los 535 proyectos gestionados por la Dirección General de Cooperación Técnica y Científica de la SRE, el 70\% (374 proyectos), responden a la lógica de recepción de colaboración externa, mientras que el 30\% (161 proyectos) emanan de la oferta mexicana (SRE-AMEXCID-DGCTC, 2011: 12).
} 
Estos datos reflejan dos cuestiones relevantes e interrelacionadas ente sí: A) En primer lugar durante 2012, México condujo su CID —en su perfil de instrumento a favor de la política exterior del país y supeditada a sus propósitos y orientaciones preferenciales - con base en cánones geoestratégicos hacia regiones y países prioritarios en su afán por complementar otras estrategias políticas y económicocomerciales direccionadas por la presidencia de México y su Cancillería. B) En segundo lugar, México diseña su CID de manera premeditada y preferencial como un ejercicio político-solidario de presencia mexicana sin intermediación alguna por parte de terceros en los países receptores. El gobierno mexicano lo hace así para maximizar la posibilidad de que tales acciones sean percibidas, en sus respectivos destinos, como ejercicios de política exterior dedicados a privilegiar la relación bilateral con el país socio ${ }^{8}$.

Gráfico 2. Oferta mexicana de Cooperación Sur-Sur bilateral por región en América Latina y el Caribe, 2012

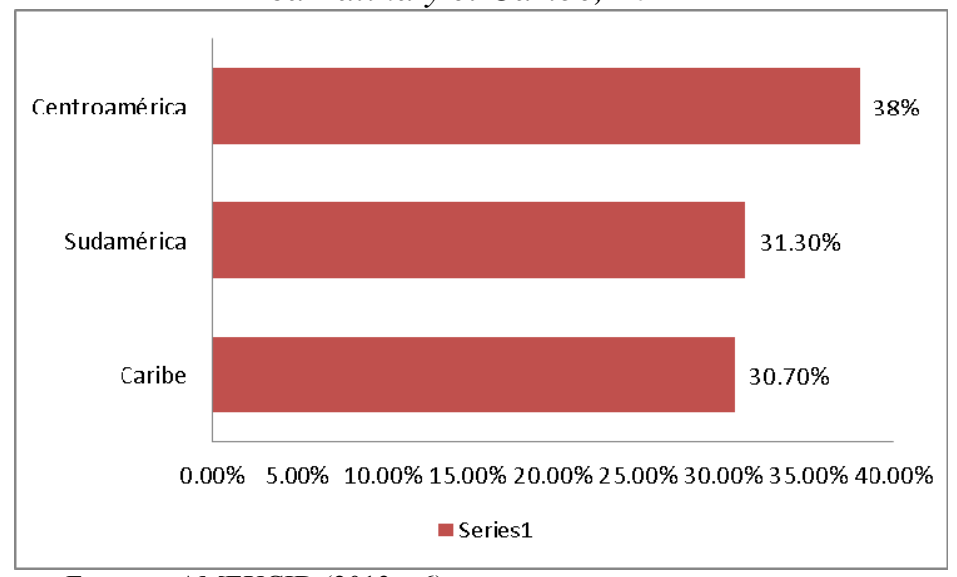

FUENTE: AMEXCID (2013a: 6).

Ahora bien, de los 153 proyectos bilaterales realizados por México en ese año, 58 fueron instrumentados en Centroamérica, lo que equivale al $38 \%$ del total. Sudamérica fue beneficiada con 48 proyectos $(31,3 \%)$, mientras que El Caribe fue socio de 47 proyectos, equiparables al $30,7 \%$ de la proactividad mexicana en este

\footnotetext{
${ }^{8}$ La priorización de la vía bilateral del ejercicio de la CSS no es en ningún sentido una carácterítica mexicana. Muestra de ello es que el Informe de la CSS Iberoamericana de 2012 editado por la SEGIB señala que las relaciones bilaterales "fueron determinantes" en la lógica de tal actividad en dicho año, mismas que se materializan en las preferencias regionales para su otorgamiento, por parte de sus respectivos oferentes (SEGIB, 2012: 6). Ello refuerza el postulado central de este artículo, en el sentido de que CID y CSS son instrumentos de política exterior condicionados por criterior geoestratégicos.
} 
rubro (Gráfico 2). Ello revela que, como ha sido la constante desde la década de los setenta, Centroamérica continúa teniendo una posición prioritaria para la cooperación mexicana ${ }^{9}$, en estricto apego a los propósitos de política exterior trazados por el gobierno federal (ibídem).

Tal y como se puede observar en el Gráfico 3 los sectores prioritarios en donde fue desplegada la cooperación internacional de México fueron los siguientes: gobierno y sociedad civil: 38 ; desarrollo agropecuario: 33; educación, ciencia y tecnología: 26; medio ambiente: 11; salud: 11; energía: 6; Turismo: 6; Vivienda y urbanismo: 4; Desarrollo económico y sector productivo: 4 (ibídem).

\section{Gráfico 3. Proyectos de Cooperación Sur-Sur bilateral por sector en América Latina y el Caribe, 2012.}

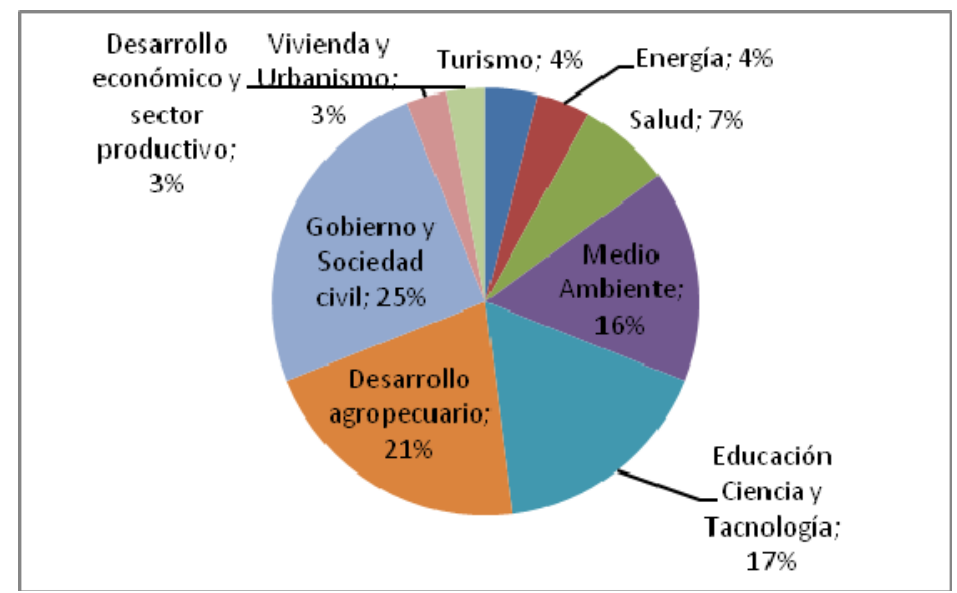

FUENTE: AMEXCID (2013a: 6).

En cuanto a los países centroamericanos (Gráfico 4) el orden fue el siguiente: Costa Rica (20 proyectos), Guatemala (11 proyectos), El Salvador (9 proyectos), Nicaragua ( 8 proyectos), Honduras ( 5 proyectos), Belice ( 3 proyectos) y Panamá ( 2 proyectos) (ibídem).

\footnotetext{
${ }^{9}$ La única excepción a este respecto se dio en 2011, cuando en ese año, con una canasta de 161 proyectos, el $48 \%$ se dirigieron a Sudamérica, el $38 \%$ a Centroamérica y el $14 \%$ a El Caribe. Esto se explica por la "mayor capacidad de absorción para implementar proyectos de cooperación por parte de los gobiernos sudamericanos, así como su mayor disponibilidad presupuestal para comprometerse en esquemas paritarios y horizontales." (SRE-AMEXCID-DGCTC, 2011: 8).
} 
Gráfico 4. Proyectos de Cooperación Sur-Sur mexicana en Centroamérica por país socio, 2012

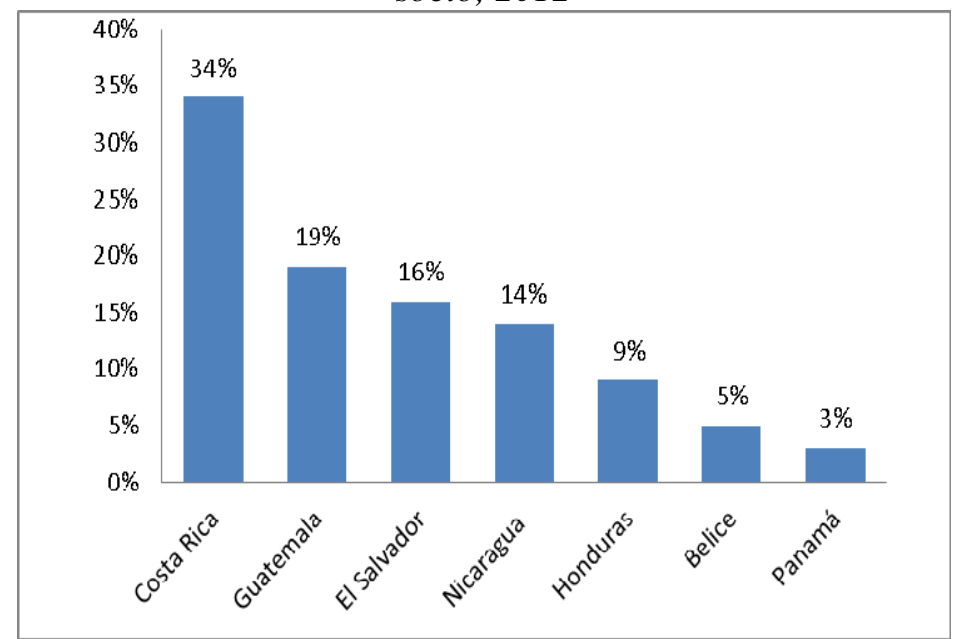

FUENTE: AMEXCID (2013a: 6).

En un segundo plano, la colaboración con Sudamérica fue realizada de manera preferencial con Chile (12 proyectos), Ecuador (10 proyectos), Perú (7 proyectos), Argentina (6 proyectos), Brasil (5 proyectos), Colombia (4 proyectos) y Bolivia (4 proyectos), (ibíd.: 7), tal y como puede observarse en el Gráfico 5.

Gráfico 5. Proyectos de Cooperación Sur-Sur mexicana en Sudamérica por país socio, 2012

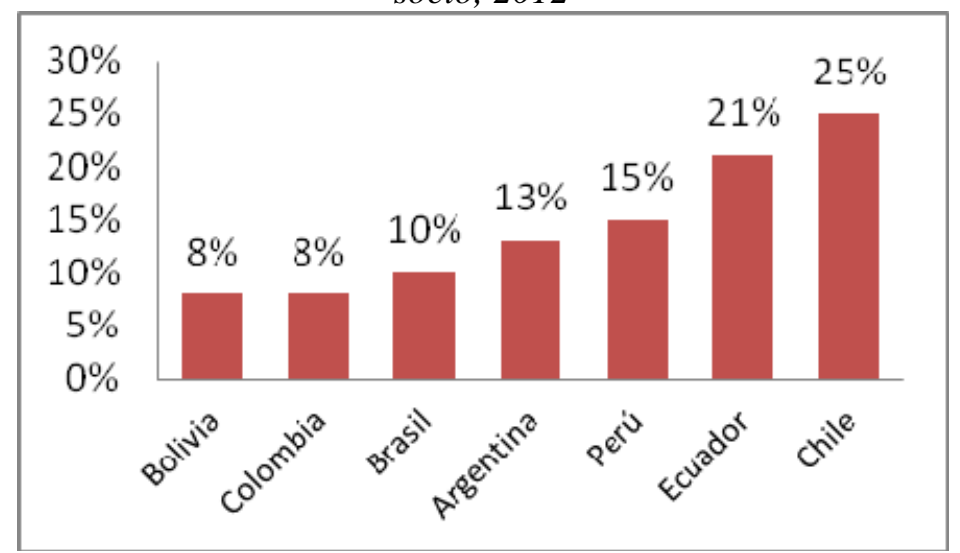

FUENTE: AMEXCID (2013a: 7). 
Finalmente, en el Caribe (Gráfico 6), por obvias razones fue Haití el principal receptor con 32 proyectos, mientras que Cuba lo hizo con nueve, Jamaica con tres, República Dominicana registró dos y Trinidad y Tobago uno (ibíd.: 8)

Gráfico 6. Proyectos de Cooperación Sur-Sur mexicana en el Caribe por país socio, 2012

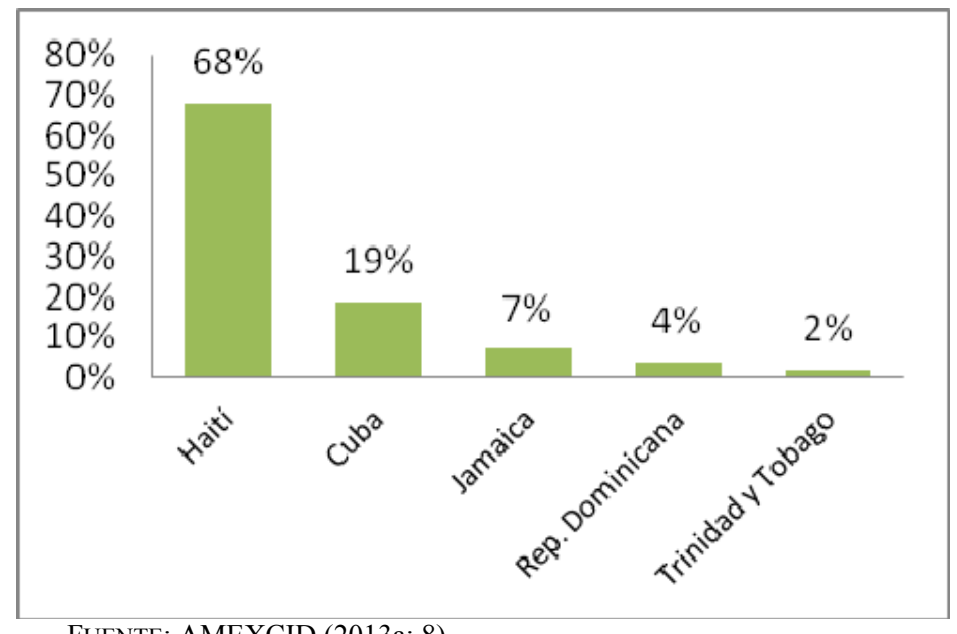

FUENTE: AMEXCID (2013a: 8).

En cuanto a atención a desastres y ayuda humanitaria, México ofreció una amplia gama de actividades financiadas con recursos nacionales de forma unilateral, tal como se estila en este tipo de acciones. Fue así como en 2012, de nueva cuenta, Latinoamérica y el Caribe, regiones geoestratégicamente prioritarias para México, ocuparon el escenario estelar, en donde Haití, Cuba, Honduras y Guatemala fueron los principales beneficiarios. En este sentido, sobresale la ayuda humanitaria con Haití, la cual ha pretendido superar el momento de crisis tras el terremoto de 2010, para pasar a proyectos de mayor alcance, de perfil desarrollista. Con base en los ocho millones de dólares ofrecidos durante la conferencia de donantes de Naciones Unidas en 2010 (aunque otorgados por la vía bilateral), la SRE a través de la AMEXCID conformó la "Alianza México por Hait'”, en donde participaron siete fundaciones privadas. Dicho ejercicio innovador permitió en 2011 conjuntar recursos financieros para la realización de diversas obras de infraestructura física permanente en ese país; una acción inédita de la cooperación internacional mexicana ${ }^{10}$.

\footnotetext{
${ }^{10}$ La Alianza México por Haití se constituyó formalmente en noviembre de 2010 mediante la firma del Convenio de Colaboración entre la SRE con las siguientes instancias privadas mexicanas: Fomento Social Banamex, Fundación Cuervo, Fundación BBVA Bancomer, Fundación Chrysler, Fundación Televisa y
} 
Cuadro 2. Acciones de ayuda humanitaria aportadas por México, 2012

\begin{tabular}{|l|l|l|l|c|}
\hline $\begin{array}{l}\text { País } \\
\text { Receptor }\end{array}$ & Fecha & Emergencia & Cooperación Mexicana & $\begin{array}{l}\text { Cooperación } \\
\text { Total en USd }\end{array}$ \\
\hline Honduras & Febrero & $\begin{array}{l}\text { Incendio } \\
\text { Granja Penal } \\
\text { Comayagua }\end{array}$ & $\begin{array}{l}\text { - Envío de cinco exper- } \\
\text { tos forenses y cuatro en } \\
\text { dactiloscopia forense } \\
\text { - Envío de medicamen- } \\
\text { tos para quemaduras }\end{array}$ & $\$ 58.542,70$ \\
\hline Cuba & Octubre & $\begin{array}{l}\text { Lluvias gene- } \\
\text { radas por el } \\
\text { paso del } \\
\text { huracán Sandy } \\
\text { en el Caribe }\end{array}$ & $\begin{array}{l}\text { - Tres mil despensas } \\
\text { alimenticias }\end{array}$ & $\$ 50.000,00$ \\
\hline Noviembre & $\begin{array}{l}\text { Paso del } \\
\text { huracán Sandy }\end{array}$ & $\begin{array}{l}\text { fibrocemento para } \\
\text { techos }\end{array}$ & $\$ 100.000,00$ \\
\hline Guatemala & Noviembre & $\begin{array}{l}\text { Terremoto de } \\
\text { región de San } \\
\text { Marcos }\end{array}$ & $\begin{array}{l}-2.737 \text { raciones alimen- } \\
\text { ticias familiares } \\
-6.534 \text { frazadas } \\
-554 \text { catres con colcho- } \\
\text { neta de algodón }\end{array}$ & $\$ 100.000,00$ \\
\hline
\end{tabular}

FUENTE: AMEXCID (2013a: 28).

Como es evidente, en línea con respecto a los propósitos de política exterior del presidente Calderón plasmados en el PND, la CID mexicana en sus diversas modalidades tuvo, en efecto, como principal eje referencial Latinoamérica y El Caribe. Por lo tanto, Centroamérica se ubica como la región focal de estas actividades, en estricto apego a la prioridad geoestratégica que el gobierno de México le ha conferido a esta región. Empero, dado que tal circunstancia si bien es necesaria es sólo uno de los insumos necesarios para conformar una política pública en CID, en el siguiente apartado se analiza el trasfondo jurídico e institucional en el que a parir de finales de 2011 se encuentra inserta la cooperación mexicana.

Fundación Azteca, cuyos recursos ascendieron a por lo menos 5,1 millones de dólares (SRE-URECIDGCTC, 2010: 6). Las cosas marchaban bien, aunque sin razones claras; la última sesión del Comité de Seguimiento de esta Alianza se realizó el 23 de julio, con lo que se cerró formalmente este programa de colaboración (Comunicado de Prensa de AMEXCID: "Concluyen oficialmente los trabajos de la Alianza México por Haiti”’, 24 julio de 2013). 


\section{Actuales transformaciones institucionales de la cooperación internacional para el desarrollo de México}

Las recientes transformaciones que la CID mexicana ha registrado de forma reciente responden a múltiples justificaciones y desafíos. Lo anterior en esencia dado que, si bien es un requisito clave, su orientación geoestratégica no es una condición suficiente para construir una política de Estado en este tema. Por ello, de forma complementaria a la premisa anterior, es necesario regular instancias dedicadas a la conformación del diseño, programación, gestión, instrumentación, seguimiento, coordinación, evaluación y difusión de la CID mexicana mediante estrategias legales e institucionales formales, de carácter permanente, que den mayor certeza respecto a los procesos y resultados obtenidos. Los anteriores elementos representan algunos de los principales desafíos para México en el tema en comento, máxime si se considera que la CID es un ejercicio del orden público, cuyo financiamiento dedicado a su oferta llegó en 2011 — según la Cancillería ${ }^{11}$ - a los cerca de 250 millones de dólares. Esta cantidad se ubica por encima de lo que a este respecto ofrecen otros países OCDE no adscritos al CAD (tal y como el caso mexicano) como Israel (173 millones de dólares), Hungría (140 millones de dólares), o Eslovaquia (87 millones de dólares).

Por ejemplo, en el plano de la gestión, se ha identificado un despliegue atomizado en múltiples sectores y ejes temáticos, tanto en el rubro de recepción como de oferta de colaboración externa. Posiblemente la principal razón de ello se encuentra en la ausencia de una estrategia integral en el ámbito de la CID, de suerte tal que no se han definido con mayor precisión aquellas temáticas de colaboración que deben ser instrumentadas, así como por la falta de una línea programática general, en donde la carencia de recursos financieros predictibles, así como el déficit en torno a la difusión de las actividades desplegadas conforman también áreas de oportunidad a este respecto (Proyecto PROCID, 2012: 13).

Sin embargo, el reto más apremiante ha sido la coordinación y concertación intergubernamental de las actividades asociadas a la CID, tanto a nivel federal como en los ámbitos estatal y municipal, lo cual se explica por la debilidad política e institucional de la entonces URECI.

De igual forma, aunque se registran avances en el seguimiento, la evaluación y la difusión de las actividades y resultados obtenidos en torno a la CID, tales procesos distan de atender las necesidades que emanan de una correcta gestión de sus procesos, lo cual le ha restado capacidad para replicar buenas prácticas y reconducir

\footnotetext{
${ }^{11}$ Este dato emana de una contabilización que la SRE realizó para avanzar en la identificación de los montos provenientes de las oficinas gubernamentales que ofrecen ejercicios de CID. El dato, si bien no fue público, ha sido citado en Prado Lallande (2013), con base en fuentes confiables de la AMEXCID.
} 
su camino en caso de lo contrario. Los elementos de oportunidad referidos responden también a la ausencia de una instancia central conglomeradora y coordinadora de los diversos actores públicos que gestionan e instrumentan cooperación al desarrollo a la luz de criterios y disposiciones afines a los lineamientos que a este respecto sean establecidos por la política exterior mediante la Cancillería, así como con base en buenas prácticas internacionales.

Para atender estos y otros retos en el ámbito de la CID en 2007 Rosario Green, en su papel de senadora por el PRI, propuso una iniciativa de Ley a este respecto (LCID), con el fin de "eliminar el rezago en el que México se encuentra en materia de ordenamiento e instrumentación de sus acciones en el ámbito de la cooperación internacional."'(Green, 2008:10) Sin embrago, el proceso que decantó en la Ley de CID de México no fue terso. Como señala Garzón, el proceso legislativo relativo a este tema resultó arduo, tortuoso y largo (Garzón, 2011: 47). Empero - y a pesar de un veto presidencial - finalmente vio la luz el 6 de abril de 2011, entrando en vigor el 16 de ese mismo mes ${ }^{12}$.

Este lineamiento jurídico señala en su artículo 37 que “...la cooperación internacional constituye una prioridad estratégica tanto para el desarrollo como para la política exterior de México". La Ley también incluye una serie de disposiciones dedicadas a concederle al Gobierno mexicano los instrumentos necesarios para promover, coordinar, ejecutar y evaluar su cooperación, con miras a poner sus acciones y efectos al servicio de su política exterior. En ese sentido, la Ley dispone la creación de la Agencia Mexicana de CID (AMEXCID), el Programa de CID (PROCID), el Registro Nacional de CID, su respectivo Sistema de Información (SIMEXCID) y el Fondo Nacional de CID. Dado que la cooperación mexicana tiene el propósito esencial de profundizar los vínculos de manera preferencial con Centroamérica, Sudamérica y El Caribe, la citada Ley en su artículo 24 indica que el Programa de CID deberá contemplar la "identificación de las áreas geográficas que resulten prioritarias para el interés de México en materia de oferta de cooperación internacional (aludiendo para tal efecto) en primer término, Centroamérica y el resto de los países de América Latina y el Caribe" (SEGOB, 2011).

Agrupados al amparo de un criterio sectorial, los objetivos y tareas establecidas por la LCID se ubican en nueve sectores prioritarios de la política mexicana de cooperación internacional: desarrollo social, educación, salud, ciencia y tecnología, medio ambiente (cambio climático y crecimiento verde), protección civil, seguridad pública, cultura y política exterior. A septiembre de 2013, es posible advertir que el proceso ha resultado lento, aunque muestra graduales avances hacia su plena vigen-

12 El contenido de la Ley se encuentra disponible en la URL: $<$ http://dof.gob.mx/nota_detalle.php?codigo=5184958\&fecha=06/04/2011>, consultado el 12 de Marzo de 2012]. 
cia $^{13}$. Por ejemplo, la AMEXCID fue creada el 28 de septiembre de 2001 (aun durante el gobierno de Felipe Calderón), heredando su estructura de manera integral de la ya citada URECI, lo cual fue criticado por varias voces, dado que la URECI no había sido diseñada con el fin de servir como una agencia. En cuanto al PROCID, SIMEXCID y FONCID, baste decir que al menos hasta octubre de 2013 no han sido formalmente instrumentados, lo cual, según información por parte de funcionarios de la Agencia, se espera se realice a finales del año 2013.

Con la llegada de Enrique Peña Nieto a la presidencia en diciembre de 2012, a diferencia de lo que ocurrió con Calderón, la política exterior parece tener un peso relativo mayor en la Administración Pública Federal en este sexenio. Quizás por ello el Plan Nacional de Desarrollo (2013-2018) asevera que "El diálogo y la cooperación con otros países, tanto en el ámbito bilateral como el multilateral, son herramientas insustituibles para la consecución de las grandes metas nacionales (Presidencia de la República, 2013: 91), reiterando que "Dado el importante legado histórico, cultural y lingüístico en común, además de la cercanía geográfica, América Latina y el Caribe constituyen el principal espacio de influencia geopolítica de México" (ibíd.: 94)". De ahí que la CID parece reevaluarse como instrumento proactivo de la política exterior mexicana tendiente a hacer de este país "un actor con responsabilidad global", al grado de que tal actividad forma parte de los cuatro pilares de política exterior del presidente Peña Nieto.

En línea con lo anterior, y considerando que "...la política exterior se basará en la CID...", (ibíd.: 99) resalta la estrategia tendiente a "Impulsar una vigorosa política de cooperación internacional que contribuya tanto al desarrollo de México como al desarrollo y estabilidad de otros países, como un elemento esencial del papel de México como actor global responsable". (ibíd.: 149-150). Como una estrategia en materia de política exterior, el PND establece "Consolidar la posición de México como un actor regional relevante, mediante la profundización de los procesos de integración en marcha y la ampliación del diálogo y la cooperación con los países de América Latina y el Caribe (apoyando) ... especialmente, en el marco del Proyecto Mesoamérica, los esfuerzos de desarrollo de las naciones de América Central y del Caribe, mediante una renovada estrategia de cooperación internacional." (ibíd.: 147).

\footnotetext{
${ }^{13}$ Un estudio más preciso sobre el estado de implementación de los preceptos de la citada Ley se encuentra en Prado Lallande (2013). La referida investigación, en concordancia con el déficit de instrumentación cabal de dicho ordenamiento jurídico, mediante una encuesta sobre percepciones que en materia de aplicación del contenido de la ley señalada aplicada a funcionarios de la AMEXCID, funcionarios de Secretarías de Estado dedicados a la cooperación internacional, así como académicos en México que se dedican a analizar a la CID de este país, arroja un resultado promedio de 5,42 puntos.
} 


\section{Cuadro 3. Instancias conformantes de la Agencia Mexicana de Cooperación Internacional para el Desarrollo, 2013}

Coordinación de Asesores (CAs), tras conservar esta figura de acuerdo al esquema anterior, se ha agregado un área jurídica para la preparación de instrumentos para las acciones de cooperación, consolidando el área de mecanismos de cooperación financiera multilateral.

Dirección General de Planeación (DGP), se crea de acuerdo a las competencias establecidas por la Ley de CID de formular y dar seguimiento al PROCID, establecer el Registro de cooperación, así como para la formulación de las políticas de CID. Recibe los aspectos que, en esta materia, llevaba la DGCTC.

Coordinación Administrativa (CAd), se fortalece esta área concentrando todas las tareas administrativas para homologar y eficientar los procesos. Junto con la Oficialía Mayor de la Cancillería, se hace cargo de la administración operativa de la Agencia, la administración de fideicomisos y análogos, así como de un presupuesto indirecto (fondos bilaterales) y la operación del SIMEXCID.

Dirección General de Cooperación y Promoción Económica (DGCPE), fusión de las otroras Dirección General de Cooperación y Promoción Económica Internacional y la Dirección General de Cooperación y Relaciones Económicas Bilaterales para aprovechar las sinergias existentes entre los asuntos que eran atendidos por dichas áreas en lo individual.

Dirección General de Cooperación Internacional para el Desarrollo (DGCID), se mantiene la materia sustantiva que anteriormente tenía la DGCTC, se agrega la tarea de coordinar, elaborar y ejecutar los lineamientos de la política internacional de cooperación educativa por la relación del intercambio educativo con la innovación, la cooperación técnica y científica, así como la ayuda humanitaria.

Dirección General de Promoción Cultural y Turística (DGPCyT), responsable de coordinar e instrumentar programas y actividades de promoción, difusión y fomento cultural y turístico de México fuera de nuestras fronteras.

Dirección General de Cooperación para Mesoamérica y el Caribe (DGCMyC), se mantienen las funciones sustantivas de promover el desarrollo de la región articulando acciones y proyectos del Proyecto Mesoamérica, pero se agrega la Dirección de Cooperación con Centroamérica y el Caribe (anteriormente en DGCTC) para crear sinergias y consolidar toda la cooperación regional de un área prioritaria de la Política Exterior Mexicana y como área natural de México como oferente de cooperación. (AMEXCID, 2013)

FUENTE: AMEXCID (2013b).

Dado que el propio PND hace alusión expresa a la AMEXCID en el sentido de comprometerse a que ésta "cumpla cabalmente su papel de coordinador y ejecutor de la cooperación internacional que provee el Estado Mexicano" (ibíd.: 150), en 2013 esta Agencia ha sido objeto de una reestructuración integral. Entre los principales objetivos de dicha Agencia resalta el que la misma "Obedezca a la política mexicana de cooperación pluritemática, geoestratégica y multimodal” (AMEXCID, 2013: 5). Para ello, se ha dispuesto que a finales del año 2013 la AMEXCID, tras una reforma a fondo de su estructura, se conforme de las áreas y Direcciones Generales señaladas en el siguiente cuadro. 
Más allá de la discusión sobre el perfil, propósitos y adecuación de varias de estas Unidades Administrativas como entes conformantes de una Agencia de CID, para este artículo lo que resulta relevante es que la nueva estructura de la AMEXCID le reserva una Dirección General, en exclusiva, a la región mesoamericana y al Caribe. ${ }^{14}$ Lo anterior se debe a la multicitada relevancia geoestratégica que reviste Centroamérica para México y, en particular, para el actual gobierno.

Figura 1. Organigrama de la AMEXCID

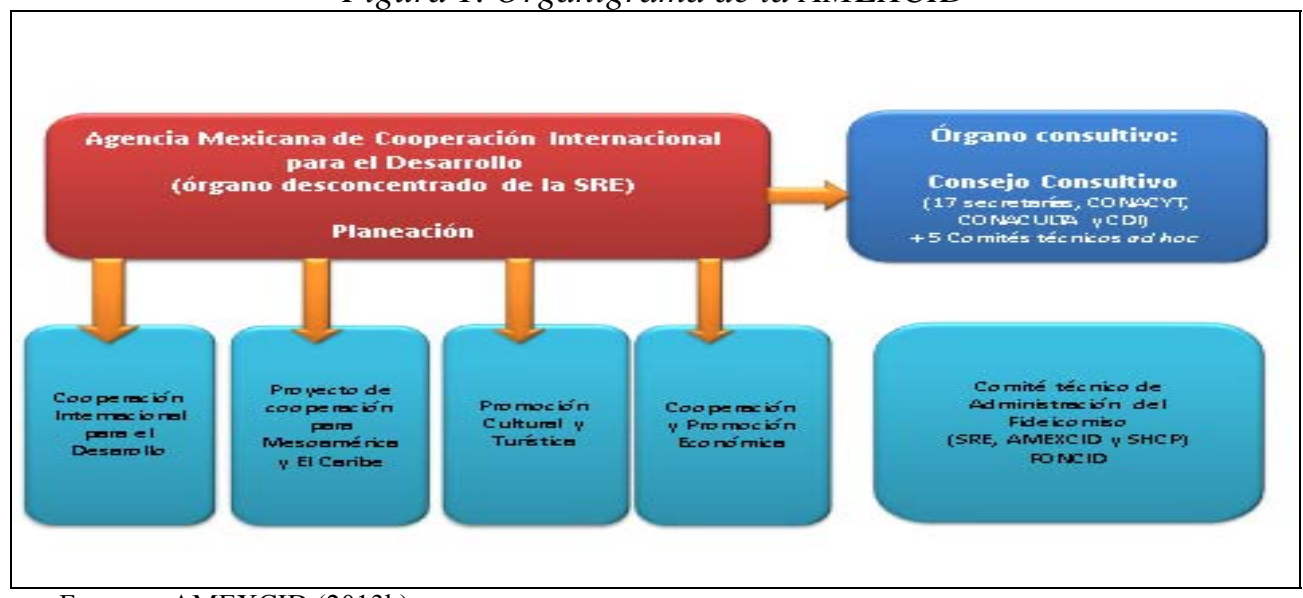

FUENTE: AMEXCID (2013b).

Ello se explica por, al menos, tres razones fundamentales: En primer lugar, se trata de una estrategia de continuidad a los logros en cuanto a experiencias previas y el subsiguiente proceso de institucionalización de la colaboración con ambas regiones generado de forma gradual durante las últimas décadas (especialmente cuando gobernaba el PRI). En segundo lugar, es un efecto directo de lo dispuesto para ello en la propia Ley, así como en el PND 2013-2018, en el sentido de conferirle a Latinoamérica y a El Caribe prioridad respecto a otras regiones del planeta. Y, en tercer lugar, es el reflejo de la voluntad política para reposicionar a dichas zonas geográficas en su dimensión de espacios de vital actuación de la política exterior del presidente Peña Nieto mediante el ejercicio de su CID.

\footnotetext{
${ }^{14}$ En realidad, el que exista una Dirección General dedicada a la colaboración ofrecida a Centroamérica no es nuevo en el organigrama de las instancias gestoras de la CD mexicana. Muestra de ello es que ya el IMEXCI (1998-2010) se conformaría, entre otras, por la Dirección General de Cooperación con Centroamérica y el Caribe que a su vez actuaba como secretariado técnico de la Comisión Mexicana para la Cooperación con Centroamérica y el Caribe (Soria, 2003: 194).
} 
En definitiva, tal y como se ha visto en este artículo, es claro que la CID de México históricamente se ha destinado de manera prioritaria a Centroamérica, Sudamérica y El Caribe. Esto es en razón a la importancia geoestratégica que de manera permanente la política exterior y los diversos gobiernos mexicanos independientemente de su adscripción política-ideológica le han conferido a dichas regiones. Más allá de esta realidad, tal y como se observa en diversos países emergentes, desde el año 2011 México vive un proceso a favor de una mayor y mejor institucionalización de los procesos inherentes a la práctica de dicha actividad, debido a que la mera concentración geoestratégica de la cooperación internacional en regiones y países resulta insuficiente, si lo que se desea es conformar una política integral de Estado a este respecto. En otras palabras, México — si bien registra continuidad y coherencia en torno a la orientación geográfica preferencial de su oferta de CID- experimenta un proceso dedicado a complementar dicha virtud en términos de establecer aquellos mecanismos programáticos, financieros, de gestión, de información y rendición de cuentas que, en su conjunto, permitan configurar una política de Estado en dicho rubro subsidiario de su política exterior, lo cual no es una condición singular mexicana, sino más bien un estado común de la gran mayoría de países emergentes que han incursionado en este tipo de actividades de presencia internacional.

\section{Consideraciones finales}

Países emergentes como México pasan por un inédito proceso en donde destaca su creciente propensión a practicar políticas y acciones de colaboración externa con base en criterios geoestratégicos supeditados a propósitos de política exterior, a efecto de conseguir aspiraciones definidas en términos políticos y económicos de forma coincidente con fundamentos solidarios. Como ha sido argumentado, la CID de México, de forma coherente con las directrices de su política exterior, ha sido destinada de manera prioritaria a Centroamérica, Sudamérica y El Caribe. En ese camino, dado que tales elementos resultan insuficientes para conformar políticas de Estado más consolidadas a ese respecto, diversos países emergentes -en donde México conforma un claro ejemplo- han echado a andar mecanismos para reforzar el marco jurídico e institucional de su CID.

Lo anterior a efecto de, mediante instancias más afinadas en materia de programación, coordinación, gestión, instrumentación, seguimiento, evaluación y visibilidad, las acciones y efectos de la colaboración externas coincidan de manera más precisa tanto con respecto a las motivaciones con base en las que este conglomerado de actividades son realizadas, como a las prioridades geoestratégicas del oferente.

En este escenario, a partir del año 2011 México ha reforzado dicho proceso, en donde la Ley de CID pretende mediante el establecimiento de nuevas configuraciones institucionales facilitar el proceso tendiente a conformar una política de Estado en este ámbito de creciente relevancia de la política exterior de los países emergen- 
tes. Esta disposición jurídica, con base en los intereses geopolíticos mexicanos, reitera la orientación espacial de la oferta de cooperación al desarrollo ubicando a Centroamérica, Sudamérica y a El Caribe como las regiones prioritarias; disposiciones que, en efecto, han sido atendidas, tal y como ha sido corroborado en este texto.

Ahora bien, el rubro más complejo, el reforzamiento de la institucionalización de la cooperación mexicana, tal y como ocurre en países emergentes similares, no ha sido cumplido a cabalidad, dada la complejidad que conlleva atender de forma íntegra a las múltiples disposiciones estipuladas en la citada Ley en los plazos de tiempo definidos para ello. Sin embargo, la nueva estructura de la AMEXCID da cuenta de una aparente renovada voluntad política para estimular dicho proceso. De ahí que aunque la mayoría de los donantes de CSS “...se caracterizan por contar con infraestructuras fragmentadas de CID" (Mawdsley, 2012: 96), precisamente para mantener o avanzar en su perfil de países emergentes de alguna manera se encuentran obligados a corregir tales inconsistencias, aunque sin renunciar a las particularidades que les identifica como oferentes alternativos o emergentes. En México tal fenómeno ha estado ocurriendo mediante los referidos procesos del orden jurídico y administrativo, mismos que pasan necesariamente por la voluntad política para consolidarlos, de la cual, al parecer, está siendo concedida por parte de la administración del presidente Peña Nieto.

El trayecto hacia la (siempre permanente) construcción de una política de Estado integral en el ámbito de CID que conglomere perspectivas geoestratégicas, políticas, económicas y solidarias mediante cánones de institucionalización adecuados, implica un propósito complejo de conseguir. Empero, México, aun con los desafíos inherentes a tal proceso, está dando pasos adelante hacia ese propósito, lo cual en caso de consolidarlos podría posicionar a este país como un Estado responsable, capaz de contribuir de forma más evidente a la conformación de una alianza global para el desarrollo desde una perspectiva del Sur, en sentido coincidente con las directrices de su política exterior.

\section{Bibliografía}

AMEXCID (2012) Proyecto de Programa Mexicano de Cooperación Internacional para el Desarrollo (PROCID). México: AMEXCID.

AMEXCID (2013a) Informe Anual de Cooperación Técnica y Científica 2012. México: AMEXCID.

AMEXCID (2013b) Reestructura AMEXCID. Documento Interno, México: AMEXCID.

Benzi, Daniele, y Zapata, Ximena (2013) "Geopolítica, economía y solidaridad internacional en la nueva Cooperación Sur-Sur: El caso de la Venezuela bolivariana y Petrocaribe". América Latina Hoy, nº. 63, 65-89. 
Chabat, Jorge (2013) "La seguridad en la política exterior de Calderón”. Foro Internacional, vol. LIII, núm. 3-4, 729-749.

Covarrubias Velasco, Ana (2013) "La política exterior de Calderón: objetivos y acciones". Foro Internacional, vol. LIII, núm. 3-4, 455-482.

Domínguez Martín, Rafael (2013) “Desmitificando la Cooperación Sur-Sur”. Blog, Centro de Información sobre la Cooperación Internacional, Bogotá, 2013. [URL: $<$ http://eficacia.info/doc_detalle.php?id=834>, consultado el 1 de Diciembre de 2013].

Erthal Abdenur, Adriana y Marcondes de Souza Neto, Danilo (2013) "Cooperación china en América Latina. Las implicaciones de la asistencia para el desarrollo". Íconos. Revista de Ciencias Sociales, núm. 47, 69-85. [URL: $<$ http://www.flacsoandes.org/iconos/images/pdfs/Iconos\%2047/I47_05D_Erthal Marcondes.pdf $>$, consultado el 30 de Noviembre de 2013].

Florido Alejo, Ángel Lorenzo, y Villaruel Mora, Aarón (2007) "Geografía y planeamiento en la región mesoamericana", en H. Cairo Carou et al.: La construcción de una región. México y la geopolítica del Plan Puebla-Panamá. Madrid: Los Libros de la Catarata / Instituto Universitario de Desarrollo y Cooperación, 67-88.

Fues, Thomas (2013) "New dynamics in South-South cooperation". The Current Column (German Development Institute, Berlin), May, 1-19. [URL: $<$ http://www.die-gdi.de/CMS-

Homepage/openwebcms3_e.nsf/(ynDK_contentByKey)/MPHG-9849TV?Open>, consultado el 28 de Noviembre de 2013].

Garzón, Luis Eduardo (2011) "El andamiaje jurídico e institucional de la Ley de Cooperación Internacional para el desarrollo de México". Revista Española de Desarrollo y Cooperación, núm. 28, 43-52.

Green, Rosario (2008) "Panorama general de la Ley General de Cooperación Internacional para el Desarrollo". Pluralidad y Consenso (Instituto Belisario Domínguez), núm. 8, 10-17.

Iglesia Caruncho, Manuel (2011) "Política exterior y política de cooperación: ¿Amistades peligrosas?". Nombres propios, Fundación Carolina. [URL: $<\mathrm{http} / / / \mathrm{www}$.fundacioncarolina.es/es-

ES/nombrespropios/Documents/NPMIglesia1104.pdf>, consultado el 10 de Marzo de 2012].

Mawdsley, Emma (2012) From Recipients to Donors. Emerging Powers and the Changing Development Landscape. Londres: Zed Books.

Ojeda, Mario (1986) México: el surgimiento de una política exterior activa. México: SEP.

Prado Lallande, Juan Pablo (2011) "La gobernabilidad de la cooperación internacional para el desarrollo de México". Revista Española de Desarrollo y Cooperación, núm. 28, 53-66. 
Prado Lallande, Juan Pablo (2013) "La cooperación internacional para el desarrollo en la política exterior del presidente Calderón". Revista Foro Internacional, vol. LIII, núm. 213-214, 816-844.

Quadir, Fahimul (2013) "Rising Donors and the New Narrative of South South Cooperation: what prospects for changing the landscape of development assistance programmes?". Third World Quarterly, vol. 32, núm. 2, 321-338.

Presidencia de la República (2006) Plan Nacional de Desarrollo 2007-2012. México: Presidencia de la R.

Presidencia de la República (2013) Plan Nacional de Desarrollo 2013-2018. México: Presidencia de la R.

Rocha, Alberto (2006) "La geopolítica de México en Centroamérica: ¿una hegemonía regional?", en D. Villafuerte Solís y X. Leyva Solano (coords.) Geoeconómía y geopolítica en el área del Plan Puebla Panamá. México: Editorial Porrúa / Centro de Investigaciones y Estudios Superiores de Antropología Social.

Secretaría de Gobernación (SEGOB) (2011) "Ley de Cooperación Internacional para el Desarrollo", Diario Oficial de la Federación, México. [URL: $<$ http://dof.gob.mx/nota_detalle.php?codigo $=5184958 \&$ fecha $=06 / 04 / 2011>$, consultado el 12 de Marzo de 2013].

Soria, Ernesto (2003) La cooperación internacional para el desarrollo y la política mexicana en la materia: Evolución y perspectivas. México: Facultad de Ciencias Políticas y Sociales, UNAM.

Secretaría General Iberoamericana (2012) Informe de la Cooperación Sur-Sur en Iberoamérica 2012. Madrid: SEGIB.

SRE-URECI-DGCTC (2010) 2010, el año de la ayuda humanitaria de la política mexicana de cooperación. México: SRE-URECI-DGCTC.

SRE-AMEXCID-DGCTC (2011) Informe Anual de Cooperación Internacional para el Desarrollo 2011. México: SRE-AMEXCID-DGCTC.

Tres, Joaquim (2013) "El surgimiento de la cooperación Sur-Sur. Hacia un nuevo ecosistema de cooperación para el desarrollo". Resumen de Políticas, Banco Interamericano de Desarrollo, IDB-PB-190, Marzo, 1-20. 